\title{
Technical and Economic Evaluations about the Integration of Co- Trigeneration Systems in the Dairy Industry
}

\author{
G. Cannistraro ${ }^{1 *}$, M. Cannistraro ${ }^{2}$, A. Cannistraro ${ }^{3}$, A. Galvagno ${ }^{1}$ and G. Trovato ${ }^{3}$ \\ ${ }^{1}$ D.I. Department of Engineering of Messina, University of Messina, Contrada di Dio, 98166 \\ Messina, Italy \\ 2 P. D. University of Messina \\ ${ }^{3}$ Freelancer Engineer - STT Engineering \& Consulting
}

Email: gcannistraro@unime.it

\begin{abstract}
The dairy industries are characterized by a high demand for electricity, and energy for heating and cooling, necessary for obtaining a finished quality product. The scope of this study is to evaluate the technical and economic feasibility of a proposed intervention in the integration of a cogeneration and trigeneration system fueled with natural gas in an existing factory service, located in the north of Italy. The proposed intervention is analyzed in order to allow for the reduction of the overall energy demand of primary energy optimizing the activity management cost. The energy demand of this activity is analyzed below. The design choice are made in terms of energy production and distribution, as well as the economic and financial assessments related to the energy integration of either the cogeneration system or by tri-generation.
\end{abstract}

Keywords: Dairy Industries, Energy, Emission Analysis, Cogeneration plants and, Tri-generation.

\section{INTRODUCTION}

The trigeneration is the consequential evolution of an integrated system of cogeneration, in fact, always using a single source of primary energy, is possible to obtain a production of electricity (or mechanical energy) and the heating for the cooling process.

The cooling process is based on the use of particular absorption cycles that take advantage of the cooling passage of the refrigerant in the liquid state in combination with the substance used as absorbent (normally lithium bromide).

Already at high efficiency, the CHP system is then flanked a further cycle at high energy efficiency, characterized by a COP (coefficient of performance), between 0.7 and 1.3, depending on the temperatures involved, and by the technologies used in the realization of the absorbers (Mono stage, two-stage, direct feeding with the exhaust gas).

In the Fig. 1 it is shown the flow diagram energy of the trigeneration plant.

\section{ANALYSIS DEMAND ENERGY AND EQUIPMENT}

The industrial plant analyzed operates, for 16 hours per day and 5,648 hours per year, and it requires heat and electricity necessary for the performance of the process.
The heating is essential for carrying out the process and for the air condition of the environments.

The energy levies are distinguished by a seasonal connotation, dependent on the energy demand for the air conditioning of the interior and for the renewal of air treatment.

The project evaluations, in the selection and in the definition of production systems, are derived from the definition of the estimated annual energy request $[1,13]$.

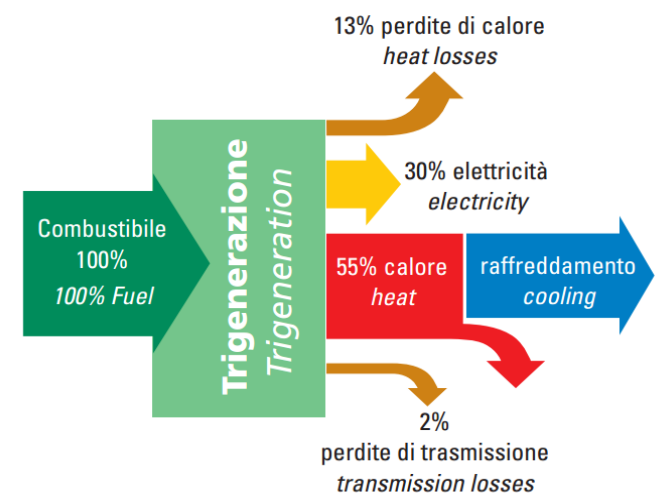

Figure 1. Energy Flow diagram of the regeneration plant 
The energy requirements have been deduced according to these two criteria:

- Analysis and evaluation of consumption for the year 2015 , through the collection of billing information, by devices registration data, direct measurements, and by data on production periods.

- Evaluation, by use of model calculation in stationary state, with the separate contributions of the heat and electricity demand for the air-conditioned building, and for that process of cooling, and the primary treatment of the air.

\section{- Thermal Energy}

The demand for natural gas for the production of thermal energy for the year 2015, is shown in Fig.2.

It is possible to appreciate that there is a substantial increase in the thermal energy demand in winter, as a result of the increase of energy demand for heating and for the air handling. In the summer we can note the opposite trend, it is lower and can be attributable at the production of hot water for the heating process.

The energy demand, in spring and autumn and in the summer have a noticeable effect on the choices concerning the design of the cogeneration plant.

The total demand for thermal energy, for the reference year, it of 221,906 cubic meters of the gas, for a total cost of procurement of $€ 88,763.00$.

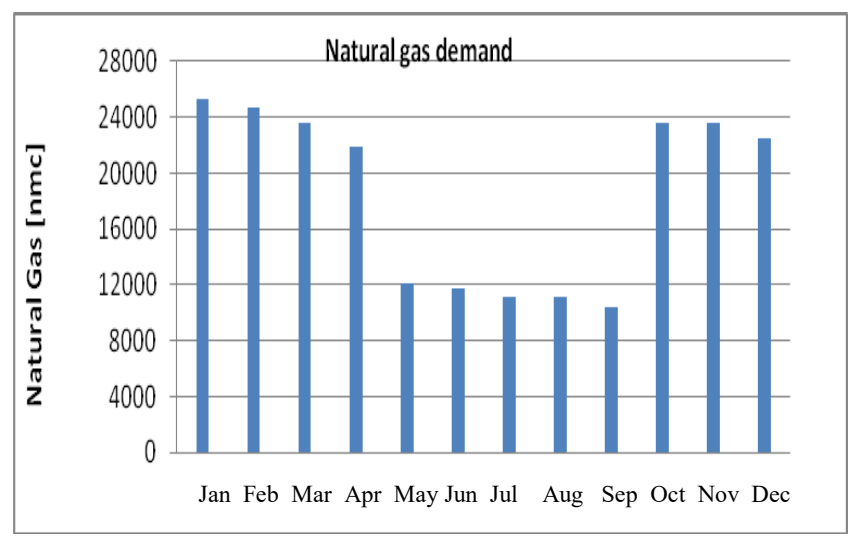

Figure 2. Natural gas demand for the 2014

\section{- Electrical Energy}

The demand for electrical energy for the production of thermal energy for the year 2015, is shown in Fig.3.

It denotes a trend approximately constant during the year, due to the power supply of all process equipment.

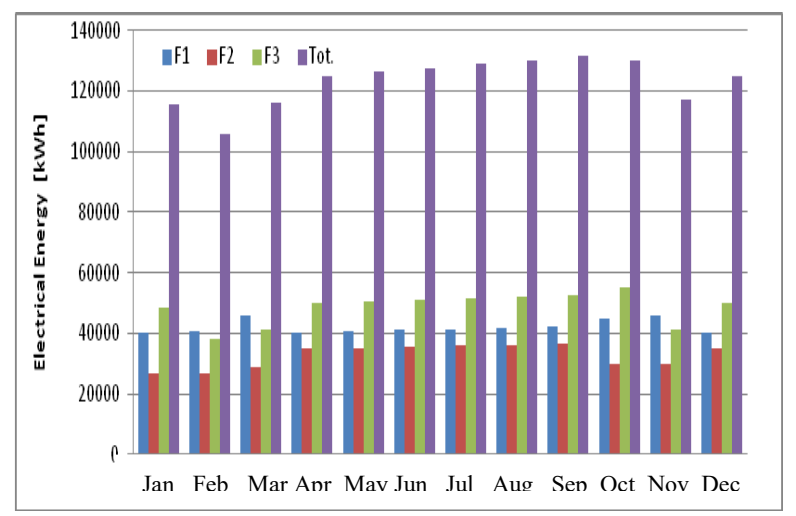

Figure 3. Electrical energy demand for the 2015

\section{- Cost of Energy}

In Tables 1 and 2 are shown below, respectively, the data of the tariff costs of natural gas and tariff data of Electrical Energy.

Table 1. Data tariff natural gas

\begin{tabular}{|l|l|l|}
\hline \multicolumn{3}{|l|}{ Data Tariff Natural Gas } \\
\hline Natural gas tariff civil use & 0,581 & $€ / \mathrm{Sm}^{3}$ \\
\hline Natural gas tariff tax-free industrial use & 0,408 & $€ / \mathrm{Sm}^{3}$ \\
\hline $\begin{array}{l}\text { Natural gas tariff defiscalised for self } \\
\text { Electricity }\end{array}$ & 0,395 & $€ / \mathrm{Sm}^{3}$ \\
\hline
\end{tabular}

Table 2. Data tariff electrical energy

\begin{tabular}{|l|l|l|}
\hline $\begin{array}{l}\text { Consumption band F1 } \\
(8-19 \text { o'clock of the day }\end{array}$ & & \\
Monday - Friday & 0,165 & $€ / \mathrm{kWh}$ \\
\hline $\begin{array}{l}\text { Consumption band F2 } \\
\text { (7-8 and } 19-23 \text { of the days Monday to } \\
\text { Friday and 7-23 on Saturdays) }\end{array}$ & 0,159 & $€ / \mathrm{kWh}$ \\
\hline $\begin{array}{l}\text { Consumption band F3 } \\
\text { (00-7 and 23-24 of the days Monday } \\
\text { to Saturday, all hours for Sundays and } \\
\text { holidays) }\end{array}$ & 0,144 & $€ / \mathrm{kWh}$ \\
\hline
\end{tabular}

\section{SIZING AND SELECTION SYSTEM OF TRIGENERATION}

The Fig. 4 shows the performance of the thermal and electrical energy demand, and the value of their relationship.

It is known as the aforesaid ratio is not constant during the period of the year, with minimum values in the summer period caused by the reduction to the thermal energy required for heating in winter.

This factor significantly affects the choice of the size of the cogeneration plant and all the plant equipment.

To tend of the relationship between the demand for heat energy and those energy power, makes it interesting the idea of solutions of the cogeneration, aimed at meeting the needs of thermal energy by reducing the use of the traditional boiler.

The main problem is the seasonality, which considerably reduces the request for heat in the summer months.

From the analysis of existing plant systems, and of the consuming profiles has been identified the possibility of installation by a tri-generation plant, used for the simultaneous production of electricity, energy heat and cooling energy, only during the summer period, in the office building and canteen service, today served by a heat pump based on vapor compression machine supplied by electric power derived from an electric counter dedicated.

The trigeneration plant has been sized considering the maximum return and the cost-effectiveness, this can be achieved only by maximizing the consumption of the energy produced; the unit of cogeneration it has been sized for the power electricity base-load and for the thermal uses.

The cogeneration system, supplied with natural gas, is composed of an internal combustion engine coupled to an alternator capable of generating electrical energy.

Moreover, thanks to the use of suitable heat exchangers, it can recover thermal energy from the exhaust fumes and the thermal energy for cooling of motor oil. 
The cooling energy is produced from absorption chiller at single effect having power of $98 \mathrm{kWf}$ and a COP of 0.8 .

To verify the suitability of the proposed co-generator, comparising the actual energy requirements of facility in question, we carried a first analysis of compatibility in terms of energy production during the entire reference year.

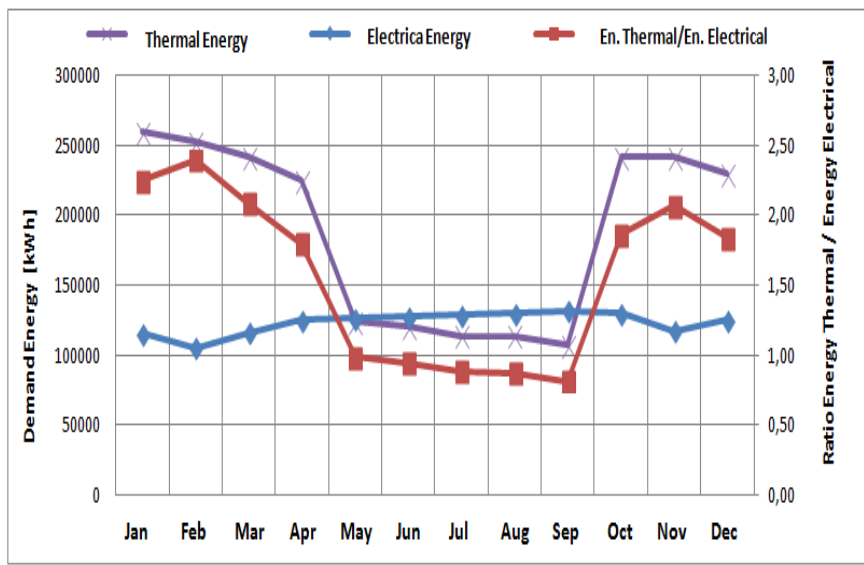

Figure 4. Performance of required thermal energy electricity and the relationship between two

In the Fig.5 end Fig. 6 are reported, for the reference year, the thermal energy demand and the energy produced by the CHP.

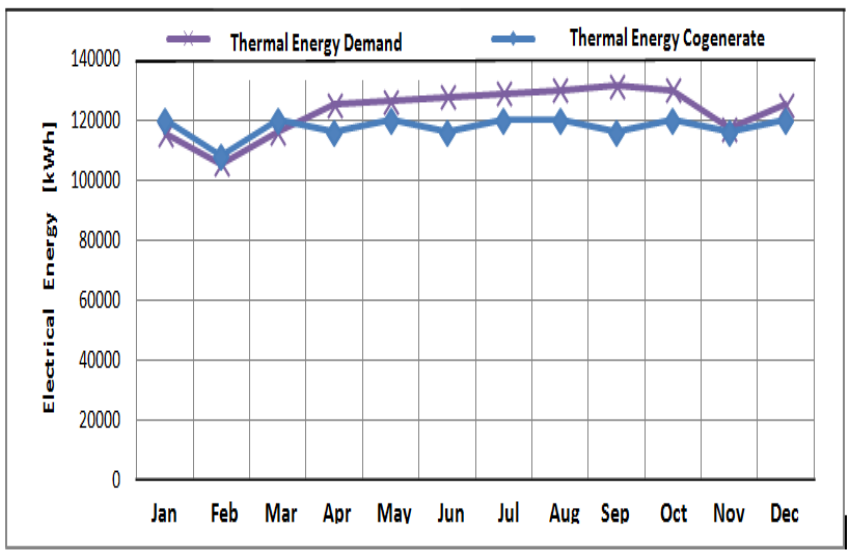

Figure 5. Energy Electricity and Thermal produced by the generator

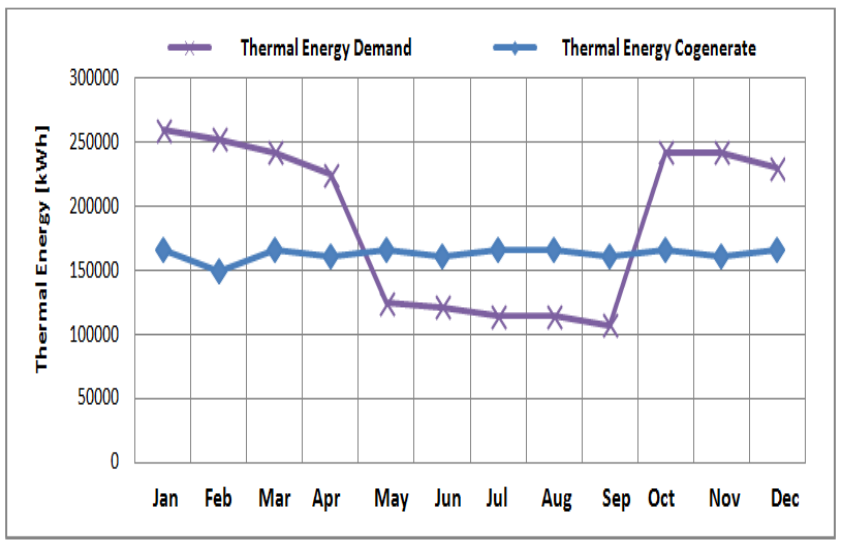

Figure 6. Thermal energy required and thermal produced cogeneration
The energy produced by the co-generator doesn't have consistent trend throughout the year, this because the number of hours of operation of the CHP were established in relation to the structure of the energy required, so as to exclude higher output than that required by the heat load.

In consequential mode, for the same number of hours of operation, it was obtained the production of electrical energy reported in Fig. 6.

Reducing the demand for thermal energy for the plants installed, it is therefore convenient a trigeneration plant.

Based on the analysis of the time curves of the electricity needs of the facility and estimating its thermal energy needs, the cogeneration system has been sized to operate fully in cogeneration in high efficiency, in a way conformed at the Decrees of the Ministry of Economic Development in August and September 2011, allowing to enjoy the benefits of this mode of operation: white certificates for use of natural gasp.

Therefore the operational conditions functioning of the proposed plants, allow to achieve the following results in terms of generated energy consumption level:

Based on the assessments

- Electricity produced: self-consumed equal a $0.97 \%$

- Thermal energy produced: self consumed equal a $100 \%$, of which $12 \%$ is intended for the production of cooling energy.

\section{CO-GENERATION HIGH PERFORMANCE}

The system Cogeneration have numerous and various incentives of the law, to the condition that it is high-efficiency cogeneration (CAR); that is a criteria for determine whether, in a given time interval, the savings of the fuels achieved by a co-generation plant is sufficiently high.

The criteria currently used for this purpose was originally introduced by Legislative Decree of 8 February 2007 n.20, which transposed into Italian law the European Directive 2004/8/EC; later, the transposition has been completed with DM August 4, 2011.

The framework is based on a numerical index called PES (Primary Energy Saving)

It is estimated that the plant in question, from the calculation of energy data obtained with operation, operates in CAR regime.

\section{ENERGY SAVINGS OBTAINED}

The Fig.7 shows the cumulative cash flow than savings, compared of a total investment estimated at around $€ 750,000$.

As we can see from the results obtained, the achievable annual savings, are equal at $171389.76 € /$ year, corresponding at $31 \%$ of the current cost of energy supply.

In the graph of Fig.7, it is shown the cumulative cash flow, we notice that the revenue achieved by the savings accumulated in the twentieth year of operation of the plant is $€ 3,000,000$.

The absorption chiller it allows to saving of $297,882.00$ $\mathrm{kWf}$, corresponding to a cost savings of $21,277 €$.

Consider the operating conditions of cogeneration is possible to assume that the plant falls within in CAR regime, and thus allows obtaining energy efficiency certificates for a total of $390 \mathrm{TEE} /$ year, corresponding to about 39,039.13 $€ /$ year. 
These interventions are in phase with European policies aimed at reducing energy needs for industrial and civil use, and produce considerable reductions of the air pollution, contributing to the improvement of quality and environmental sustainability [14,24].

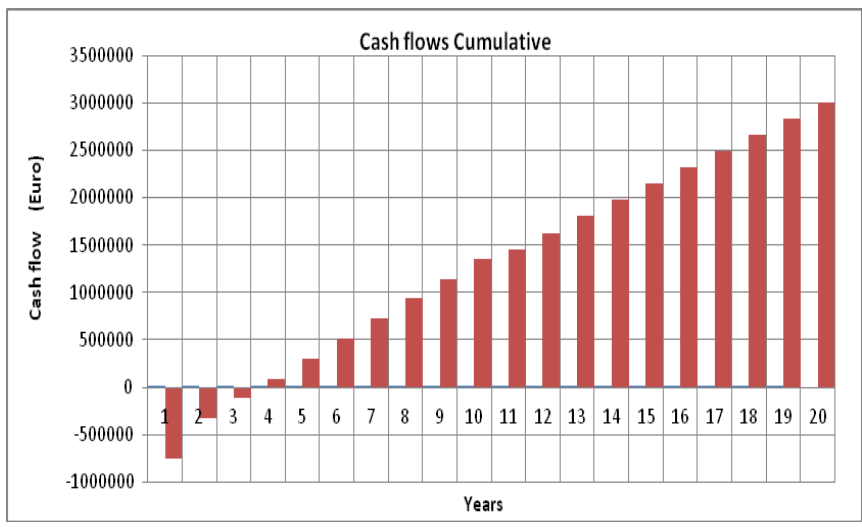

Figure 7. Cash flows cumulative

Therefore, the economic evaluation took into account the energy efficiency certificates recognized until the tenth year after the entry into operation of the cogeneration plant.

In the same graph is shown as the fourth year of operation, we will reach the compensation of investment through the savings achieved by the cost of investment

\section{CONCLUSIONS}

In the present decade, the deterioration of air quality in urban areas has become a global problem.

The variety of atmospheric pollutants in urban, present in the centers of the cities, is produced by industrial plants and/or civil installations for the air climatisation, represent a significant threat to the future health of our planet.

These interventions are according to European policies aimed at reducing energy needs for industrial and civil use, and produce considerable reductions of the air pollution, and contribute to the improvement of quality and environmental sustainability.

The study makes it possible to demonstrate how the creation of a trigeneration system: heat, electricity and cooling, allows to energy savings and of economic management.

The correct selection of the size of the CHP is of paramount importance for the optimization of energy savings achieved and for reduction of the payback period.

In this case, we demonstrate how the maximization of operating hours, in which happens self consumption of heat and electricity cogenerated, increases the investment convenience.

The integration of an absorption refrigeration system allows to recover the heat energy, otherwise dissipated during the summer period, keeping the chosen size of the CHP aligned to the electricity demand of the plant.

\section{REFERENCES}

[1] Sachdeva, R. C., Fundamental of Engineering Heat and Mass Transfer, pp. 201 and 245.

[2] Myer Kutz, Mechanical Engineering Hand Book, vol. 23, 1987.
[3] Kotendaraman, C.P. and Subramaniam S., Heat and Mass Transfer Data Book, vol. 65, 1990.

[4] Wood Heart and Willcox, Modern refrigeration and Air Conditioning, vol. 68, 2009.

[5] Abdul Khaliq, "Exergy analysis of gas turnine trigeneration system for combinate production of power heat and refrigeration," International Journal of Refrigeration, Elsevier, pp. 1-12, 2008.

[6] A. Khaliq and S. C. Kuashik, "Thermodynamic performance evaluation of combustion gas turbine cogeneration system with reheat," Applied Energy, Elsevier, pp. 1785-1795, 2004.

[7] Teopa Calva E. and Picon Nunez M., "Integration of tri-generation system," Applied Thermal Engineering, Elsevier, vol. 25, pp. 973-984, 2005.

[8] J. Bassols, B. Kuckelkorn, J. Langreck, R. Schneider and H. Veelken, "Trigeneration in the food Industry," Applied Thermal Engineering, Pergamon Press, 22, pp. 595-602, 2002.

[9] Ziher D. and Poredos A., "Economics of a Trigeneration system in a Hospital," Applied Thermal Engineering, Elsevier, vol. 26, pp. 595-602, 2002.

[10] Joel Hernandez-Santoyo and Agusto Sanchez-Cifuentes, "Trigeneration an alternative for energy saving," Applied Thermal Engineering, Elsevier, vol. 76, pp. 219-227, 2003.

[11] E. Minciuc O. Le Corre, V. Athanasovici, M. Tazerout and I. Bitir, "Thermodinamic analysis of trigeneration with absorption chilling machine," Applied Thermal Engineering, Pergamon Press, vol. 23, pp. 1301-1405, 2003.

[12] Galip Temir and Durriye Bilge, "Thermo-economic analysis of tri-generation system," Applied Thermal Engineering, Elsevier, vol. 24, pp. 2689-2699, 2004.

[13] M. Cannistraro, S. G. Leonardi, D. Aloisio, E Patti, C. Pace, W. Khalaf, N. Donato and G. Neri, "Development of electronic-nose technologies for biomedical applications," XVII Annual Conference AISEM, Brescia, Feb.5-7 2013

[14] G. Cannistraro, M. Cannistraro and R. Restivo, "Some observations on the radiative exchanges influence on thermal comfort in rectangular open-space environments," International Journal of Heat \& Technology, vol. 33, pp. 79-84, 2015. DOI: 10.18280/ijht.330213.

[15] G. Cannistraro, M. Cannistraro and R. Restivo, "The local media radiant temperature for the calculation of comfort in areas characterized by radiant surfaces," International Journal of Heat \& Technology, vol. 33, no. 1, pp. 115-122, 2015. DOI: $10.18280 /$ ijht.330116.

[16] M. Cannistraro, G. Cannistraro A. Piccolo and R. Restivo, "Potential and limits of oxidative photocatalyses and possible applications in the field of cultural heritage" Advanced Materials Research, vol. 787, pp. 111-117, Trans Tech Publications, Switzerland, 2013.

[17] G. Cannistraro, M. Cannistraro, A. Cannistraro, A. Galvagno and G. Trovato, "Evaluation of the convenience of a citizen service district heating for residential use. A new scenario introduced by high efficiency energy system," International Journal of Heat \& Technology, vol. 33, no. 4, pp. 167, 172, 2015. DOI: $10.18280 / \mathrm{ijht} .330421$.

[18] G. Cannistraro, M. Cannistraro and R. Restivo, "Messina's Historical Buildings after the Earthquake of 1908: Energy and Environmental Analysis through a 
Global Screening Methodology," International Journal of Heat \& Technology, vol. 31, no. 2, 2013, pp.155, 158, 2013. DOI: $10.18280 /$ ijht.310221.

[19] G. Cannistraro, M. Cannistraro, A. Galvagno and G. Trovato, "Preliminary design study of a CHP Plant in service for an hotel accommodation," WSEAS, Venice 29-31, Jan. 2016.

[20] G. Cannistraro and M. Cannistraro, "Hypothermia Risk, monitoring and environment control in operating rooms," International Journal of Heat \& Technology, vol. 34, no. 2, June 2016, pp. 165 and 171. DOI: 10.18280/ijht.340202.

[21] G. Cannistraro, A. Cannistraro M. Cannistraro, A. Galvagno and G. Trovato, "Analysis of the air pollution in the urban center of four sicilian cities," vol. 34, Special Issue 2, October 2016, to be published.

[22] G. Cannistraro, M. Cannistraro, A. Galvagno and G. Trovato, "Reduced of demand of energy cooling in the ced, centers of processing data, with use of freecooling systems," International Journal of Heat \& Technology, vol. 34, no. 3, 2016, pp. 408 and 502, 2016. DOI: $10.18280 /$ ijht. 340321.

[24] G. Cannistraro, M. Cannistraro and A. Cannistraro, "Evaluation of the sound emissions and climate acoustic in proximity of one railway station," vol. 34 , Special Issue 2, October 2016, to be published. 